\title{
Collapse, hoarseness of the voice and swelling and bruising of the neck: an unusual presentation of thoracic aortic dissection
}

\author{
W Al-Hity, M J Playforth
}

\begin{abstract}
A 66 year old woman presented to the accident and emergency department with history of collapse, hoarseness of the voice, and swelling and bruising of the neck. The diagnosis was not initially obvious because of the absence of chest pain. The findings on the radiograph of the soft tissue of the neck and chest radiograph suggested the need for computed tomography of the neck and chest. This confirmed the cervical haematoma and typical signs of aortic dissection. This unusual presentation of thoracic aortic dissection is discussed below.

(Emerg Med f 2001;18:508-509)
\end{abstract}

Keywords: hoarseness; haematoma; thoracic aortic dissection

\section{Case report}

A 66 year old woman presented to the accident and emergency department after she collapsed at home. She complained of tiredness, and a hoarse voice, but remembered nothing of the collapse. She had not complained of any chest pain.

On examination she was pale. Her temperature was $36.9^{\circ} \mathrm{C}$, pulse rate was 114 beats per minute, sinus rhythm, blood pressure was $165 / 90 \mathrm{~mm} \mathrm{Hg}$, and oxygen saturation was $85 \%$ on air. She had marked swelling and ecchymosis, mainly at the root of the neck (fig 1). The larynx was slightly tender. There was no surgical emphysema in the neck.

Examination of the chest revealed bruising of the upper anterior chest wall. On auscultation decreased air entry in the left upper zone was apparent. Again the absence of surgical emphysema was recorded.

Abdominal examination was unremarkable.

Accident and Emergency Medicine Department, Pontefract General Infirmary, Friarwood Lane, Pontefract, West Yorkshire WF8 1PL, UK

Correspondence to: Mr Al-Hity

(wajdy84@hotmail.com)

Accepted for publication 15 March 2001

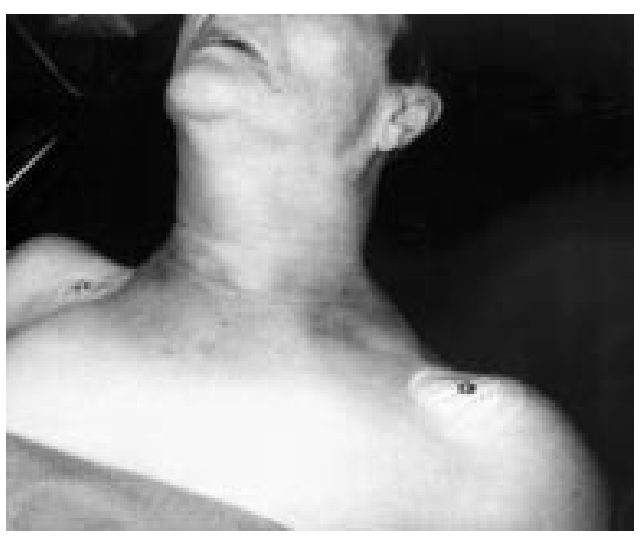

Figure 1 Swelling and bruising of the neck and upper anterior chest wall
The initial clinical diagnosis was of trauma to the neck resulting from the fall causing laryngeal damage and concomitant vascular injury.

Initial treatment was oxygen $10 \mathrm{l} / \mathrm{min}$ via a mask, intravenous access was secured and blood sample obtained for full blood cell count, urea and electrolytes, creatinine kinase, random blood glucose, and cross matching of four units of blood was arranged. Her ECG was normal.

Blood results showed $\mathrm{Hb} 12.1 \mathrm{~g} / \mathrm{dl}$, white cell count $22.1 \times 10^{\%}$, platelets $319 \times 10^{9} / 1$, urea and electrolytes were normal, creatinine kinase $724 \mathrm{U} / 1$ (normal range 25-170 U/1) and glucose $7.9 \mathrm{mmol} / 1$.

Radiographs of the soft tissues of her neck and of the chest were arranged. These showed a marked increased in the width of soft tissue shadow anterior to the cervical spines, widening of the mediastinum, and a round opacity in the left upper zone.

Computed tomography of the neck and chest was requested, which confirmed the neck haematoma, which had arisen from thoracic aortic dissection that extended from the arch of the aorta down to the abdominal aorta (DeBakey classification III).

The patient was referred to the regional cardiothoracic centre and underwent subsequent surgical repair, but unfortunately she died in the intensive care unit on the same night.

\section{Discussion}

Acute aortic dissection is the most common catastrophic event involving the aorta; furthermore, its incidence may be increasing in the industrialised world. It has been estimated that the incidence of aortic dissection in the United States may be as high as 10 to 20 cases per million population per year. ${ }^{1}$

Aortic dissection is caused by the sudden development of a tear in the aortic intima, opening the way for a column of blood driven by the force of the arterial pressure to enter the aortic wall destroying the media and stripping the intima from the adventitia for a variable distance along the length of the aorta. ${ }^{2}$

A number of predisposing conditions are associated with aortic dissection. The most common of these is hypertension. Others include Marfan's syndrome, pregnancy, chest trauma, and iatrogenic causes. ${ }^{3}$

In the setting of chronic hypertension, aortic dissection should be considered a diagnostic possibility in patients presenting to the emergency department with acute chest or back pain. Left untreated, about $75 \%$ of patients 
with dissections involving the ascending aorta die within two weeks of an acute episode. With successful initial treatment, the five year survival rate increases to $75 \%$. Hence, timely recognition of this disease entity coupled with urgent and appropriate treatment is the key to a successful outcome in a majority of the patients. ${ }^{2}$

Acute aortic dissection may have variable presentations, making the diagnosis clinically challenging. ${ }^{3}$ Chest pain is the key symptom, usually described as migratory intrathoracic tearing sensation irradiating towards the lumbar region. The other symptoms become meaningful with this pain: paraplegia, acute peripheral ischaemia, hemiplegia. ${ }^{6}$ Syncope or coma may also be acute manifestation of aortic dissection. ${ }^{1}$

About $10 \%$ of aortic dissections are painless and may present with symptoms secondary to the complications of the dissection. ${ }^{7}$

This report describes an unusual presentation of aortic dissection with collapse, swelling, and ecchymosis of the neck.

Other rare presentations of aortic dissections include unilateral lower extremity numbness, ${ }^{5}$ stroke, consumptive coagulopathy, and gastrointestinal haemorrhage, ${ }^{8}$ and aorto-right atrial fistula. ${ }^{9}$

All patients in whom aortic dissection is suspected, even if the index of suspicion is very low, should undergo one of the available diagnostic procedures: aortography, computed tomography, magnetic resonance imaging. ${ }^{10}$

The accuracy of aortic angiogram is approximately $90 \%$, however this test is more lengthy than newer imaging techniques, and it prolongs the time from the onset of intimal tear to time of operation and increases mortality and morbidity. It has been shown that computed tomography, echocardiography, or magnetic resonance imaging can be very reliable in documenting the origin of the dissection in the fastest possible time and are preferable. ${ }^{3}$

In conclusion, aortic dissection may have variable presentations, making the diagnosis clinically challenging. Early recognition of the condition is likely to affect the prognosis.

Funding: none.

Conflicts of interest: none.

1 Robert B, Rutherford MD. Vascular surgery. 4th ed. Philadelphia: W B Sounders, 1995:1088-93.

2 Hartmann T, Kolev N, Zimpfer M. A rare presentation of thoracic aortic dissection as detected by transoesophageal thoracic aortic dissection as detected by transoesoph

3 Sabiston DC Jr, Spencer FC. Surgery of the chest. 6th ed. Sabiston DC Jr, Spencer FC. Surgery of
Philadelphia: W B Sounders, 1995:1345.

4 Chen K, Varon J, Wenker OC, et al. Acute thoracic aortic dissection: the basics. F Emerg Med 1997;15:859-67.

5 Beach C, Manthey D. Painless aortic dissection presenting as left lower extremity numbness. Am $f$ Emerg Med 1998;16:49-51. 6 Kirkorian G, Bonnefoy E, Chavalier P, et al. Acute dissection
of the thoracic aorta. Symptoms and complications. Arch Mal Coeur Vaiss 1997;90:1793-7.

7 Khan IA, Wattanasauwan N, Ansari AW. Painless aortic dissection presenting as hoarseness of the voice: cardiovocal syndrome: Ortner's syndrome. Am f Emer Med 1999;17: 361-3.

8 Sadhwani D, O'Mara K. Acute dissecting thoracic aortic aneurysm presenting with stroke, consumptive coagulopathy, and gastrointestinal hemorrhage. $\mathcal{F}$ Emerg Med 1999; 17:631-5.

9 Scalia D, Rizzoli G, Scomparin MA, et al. Aorto-right atrial fistula: a rare complication of aortic dissection type A. A report of two cases. F Cardiovasc Surg (Torino) 1997;38: 619-22.

10 Sarasin FP, Louis-Simonet M, Gaspoz JM, et al. Detecting acute thoracic aortic dissection in the emergency department: time constraints and choice of the optimal diagnostic test. Ann Emerg Med 1996;28:278-88. 